\title{
PENGARUH PROMOSI KESEHATAN DAN KESELAMATAN KERJA (K3) TERHADAP PENGETAHUAN DAN SIKAP PEMULUNG DI TEMPAT PEMBUANGAN AKHIR MEDAN MARELAN
}

\author{
The Effect Of Health And Safety Working Promotion In Increasing Of Scavengers Knowledge And \\ Attitude In Landfill Terjun Medan Marelan
}

\author{
Rima Yolanda ${ }^{1}$, Agnes Ferusgel ${ }^{1 *}$, Nuraini ${ }^{1}$ \\ 1 Institut Kesehatan Helvetia \\ *Email : agneslppmhelvetia@gmail.com
}

\begin{abstract}
Lack of knowledge and attitude on scavengers causes a lot of ignorance and lack of understanding about the importance of knowing occupational health and safety that can prevent work accidents or work-related illnesses, to overcome this health and safety promotion. This study aims to determine the Effect of Occupational Health and Safety Promotion on Increasing Knowledge and Attitude of Informal Workers at the Marelan Medan Final Disposal Site. The design of this study was an quasi experiment with one group pre-test and post test. The population in this study were as many as 220 people with the sampling technique was simple random sampling with a total sample of 40 people. Data analysis with Wilcoxon test statistic. The results of the study showed that there was an effect of health and safety promotion on the knowledge and attitude of scavengers in the final disposal area of the marelan field. It is recommended that scavengers continue to improve their knowledge of occupational health and safety. It is hoped that the regional government will always carry out promotional programs related to Occupational Health and Safety in the informal sector.
\end{abstract}

Keywords : Promotion, Knowledge, Attitude, Scavengers

\begin{abstract}
Abstrak
Kurangnya pengetahuan dan sikap pada pemulung menyebabkan banyak ketidaktahuan dan ketidakpahaman tentang pentingnya untuk mengetahui kesehatan dan keselamatan kerja yang dapat mencegah terjadinya kecelakaan kerja atau penyakit akibat kerja, untuk mengatasi hal tersebut promosi kesehatan dan keselamatan kerja. Penelitian ini bertujuan untuk mengetahui Pengaruh Promosi Kesehatan dan Keselamatan Kerja Terhadap Peningkatan Pengetahuan dan Sikap Pekerja Informal di Tempat Pembuangan Akhir Medan Marelan. Desain penelitian ini adalah Quasi-Eksperimen dengan rancangan one group pretest and post test. Populasi dalam penelitian ini adalah sebanyak 220 orang denganteknik pengambilan sampel adalah simple random sampling dengan jumlah sampel sebanyak 40 orang. Analisis data dengan statistic uji wilcoxon. Hasil penelitian menunjukan terdapat pengaruh promosi kesehatan dan keselamatan kerja dengan pengetahuan dan sikap pemulung di tempat pembuangan akhir medan marelan. Disarankan kepada pemulung agar tetap meningkatkan pengetahuan tentang kesehatan dan keselamatan kerja. Diharapkan pemerintah daerah agar selalu mengadakan program promosi terkait Kesehatan dan Keselamatan Kerja dibidang sektor informal.
\end{abstract}

Kata kunci : Promosi, Pengetahuan, Sikap, Pemulung 


\section{PENDAHULUAN}

Keberadaan pemulung berperan dalam pembangunan meskipun tampaknya remeh. Di samping perannya dalam menciptakan lapangan kerja untuk dirinya sendiri dalam memenuhi penghasilan untuk keluarga. Profesi pemulung dapat digolongkan ke dalam definisi kerja sektor informal, yaitu sebagai bagian dari sistem ekonomi yang tumbuh untuk menciptakan kerja dan bergerak dibidang produksi serta barang dan jasa dan dalam usahanya menghadapi keterbatasan modal, keterampilan, dan pengetahuan. (Nurfajriantu, 2017).

Bahaya kerja pada pemulung dapat berupa penyakit menular dan tidak menular. Keluhan yang terdapat/yang sering dialami oleh pemulung adalah munculnya gangguan sistem pernafasan, diare serta penyakit kulit. Yang menjadi permasalahan lain di TPA adalah perilaku kerja pada pemulung. Perilaku pekerja dalam hal ini adalah penggunaan alat pelindung diri (APD) dan personal hygiene pemulung yang masih kurang diterapkan pada pemulung. Berdasarkan pengamatan yang dilakukan di TPA Terjun masih banyak pemulung tidak menggunakan APD lengkap pada saat bekerja. Personal hygiene pada pemulung juga merupakan faktor risiko keluahan penyakit diare, kecacingan dan sebagainya. Oleh karena itu perlu adanya promosi kesehatan dan keselamatan kerja dikalangan tenaga kerja, pengusaha, masyarakat merupakan hal yang penting bagi perusahaan, guna terciptanya hubungan industri yang harmonis, dinamis serta berkeadilan yang menjamin ketenangan usaha, ketenangan kerja dan produktivitas melalui pengembangan peningkatan pengetahuan pekerja. (Laili, 2017).

Promosi kesehatan pada hakikatnya adalah upaya intervensi yang ditunjukan pada faktor perilaku. Namun pada kenyataannya tiga faktor yang lain perlu intervensi pendidikan atau promosi kesehatan juga, karena perilaku juga berperan pada faktor-faktor tersebut (Notoadmodjo, 2012). Apabila lingkungan baik dan sikap masyarakat positif maka lingkungan dan fasilitas tersebut niscaya akan dimanfaatan atau digunakan oleh masyarakat.Secara umum ada beberapa faktor yang mempengaruhi perubahan keadaan yang disebabkan oleh promosi, yaitu adalah keadaan pribadi sasaran, keadaan lingkungan fisik, keadaan social dan budaya masyarakat, kemudian aktifitas kelembagaan yang tersedia dan menunjang penyuluhan. Promosi ditempat kerja harusnya dilakukan secara komprehensif, partisipasi dan kewenangan yang ada. Promosi kesehatan di tempat kerja hendaknya di kembangkan dengan melibatkan kerja sama dengan berbagai sektor yang terkait dan melibatkan beberapa kelompok organisasi masyarkat yang ada sehingga lebih mantap serta berkesinambungan. (Kholid, 2012).

Penelitian yang dilakukan oleh Rafiah Maharani Pulung dengan judul Promosi Keselamatan dan Kesehatan Kerja (K3) Terhadap Peningkatan Pengetahuan dan Sikap Tentang Penggunaan Alat Pelindung Diri (APD) di Laboratorium pada Siswa di SMK Kimia Tunas Harapan Jakarta Timur Tahun 2017. Disimpulkan bahwa, ada hubungan promosi K3 dengan pengetahuan dan sikap siswa tentang penggunaan APD di Laboratorium Kimia SMK Kimia Tunas Harapan. Diharapkan adanya perhatian khusus kepada siswa dalam penyediaan APD yang sebaiknya disediakan dari pihak sekolah sebelum dilakukannya Praktikum Laboratorium (Rafiah, 2017).

Tempat pembuangan akhir merupakan tempat dimana sampah mencapai tahap terakhir dalam pengelolaanya sejak mulai timbul di sumber, pengumpulan, pemindahan dan pengangkutan, pengolahan dan pembangunan.Paradigma tempat pembuangan akhir (TPA) yang dulu merupakan tempat pembuangan akhir sampah, berdasarkan Undang-Undang Nomor 18 menjadi tempat pemprosesan akhir sampah didefenisikan sebagai pemproSsesan akhir sampah dalam bentuk pengambilan sampah dan residu hasil pengelohan sebelumnya kelingkungan secara aman (Siregar, 2017).

TPA sendiri yang menjadi permasalahannya adalah perilaku kerja pemulung, dalam hal ini perilaku pemulung dalam penggunaan Alat Pelindung Diri dan personal hygine pemulung yang masih kurang diterapkan sehingga masih adanya kecelakaan atau penyakit akibat kerja yang di dapat oleh pemulung. Kemudian berdasarkan pengamatan yang dilakukan di TPA Terjun masih banyaknya 
pemulung yang tidak menggunakan Alat Pelindung Diri (APD) yang lengkap pada saat bekerja (Nasution, 2017).

Berdasarkan survei awal yang dilakukan oleh peneliti di Kelurahan Terjun Kecamatan Medan Marelan tepatnya di TPA Terjun yang merupakan tempat pengolahan sampah yang masih beroperasi di Kota Medan yang memiliki luas $137.563 \mathrm{~m} 2$ dan mulai beroperasi sejak tahun 1993 dengan sistem open dumping. Terdapat pemulung yang tidak perhatian kesehatan serta keselamatan dirinya sehingga banyaknya pemulung yang menderita gangguan kulit akibat tidak memakai alat pelindung diri (APD), dimana pemulung selalu mengeluh dengan gangguan kulit, maka denganhal tersebut saya mengambil judul dengan Pengaruh Promosi Kesehatan dan Keselamatan Kerja Terhadap Peningkatan dan Pengetahuan sikap Pekerja Pemulung di TPA Medan Marelan.

Berdasarkan latar belakang maka penulis merasa tertarik untuk melakukan penelitian dengan judul pengaruh promosi kesehatan dan keselamatan kerja terhadap peningkatan pengetahuan dan sikap pekerja pemulung di TPA Terjun Kecamatan Medan Marelan. Adapun tujuan umum dari penelitian ini adalah untuk mengetahui pengaruh promosi kesehatan dan keselamatan kerja terhadap peningkatan pengetahuan dan sikap pekerja pemulung di TPA Terjun Kecamatan MedanMarelan.

\section{BAHAN DAN METODE}

Desain penelitian ini adalah Quasi Eksperimen dengan rancangan one group pre-test and post test, yang bertujuan untuk mengetahui pengaruh promosi kesehatan dan keselamatan kerja terhadap peningkatan pengetahuan dan sikap pekerja pemulung di Keluruhan Terjun Kecamatan Medan Marelan. Dimana dalam rancangan ini tidak ada kelompok pembanding (kontrol), tetapi dilakukan observasi pertama yang memungkinkan peneliti dapat menguji perubahan yang terjadi setelah adanya perlakuan. Analisis data dengan uji wilcoxon.
Jenis data penelitian yaitu data primer dari hasil wawancara terhadap pemulung dengan menggunakan kuesioner memberikan penjelasan singkat tentang tujuan dan penelitian serta cara pengisian kuesioner dan ditanyakan kepada responden apabila ada hal-hal yang tidak dimengerti, data sekunder adalah data yang diperoleh dari hasil dokumentasi oleh pihak lain, Data sekunder berupa profil TPA Kelurahan terjun Kecamatan Medan Marelan, data tersier yang diperoleh dari berbagai referensi yang sangat valid, sepertijurnal, textbook, dan sumber elektronik.

\section{HASIL DAN PEMBAHASAN}

Setelah dilakukan penelitian terhadap 40 responden kepada pemulung di TPA Terjun Kecamatan Medan Marelan tahun 2018, maka di peroleh data pada tabel 1.

Tabel 1. Distribusi Frekuensi Responden Berdasarkan Karakteristik Responden di Tempat Pembuangan Akhir Sampah Medan Marelan

\begin{tabular}{lll}
\hline $\begin{array}{l}\text { Karakteristik } \\
\text { Responden }\end{array}$ & $\begin{array}{l}\text { Jumlah } \\
\text { Frekuensi } \\
\text { (f) }\end{array}$ & Persen (\%) \\
\hline Umur & & \\
17-32tahun & 6 & 15,0 \\
33- 48tahun & 18 & 45,0 \\
49 - 64tahun & 14 & 35,0 \\
$>64$ tahun & 2 & 5,0 \\
\hline Jenis Kelamin & & \\
Laki-laki & 24 & 60,0 \\
Perempuan & 16 & 40.0 \\
\hline Pendidikan & & \\
Tidak tamat SD & 14 & 35,0 \\
SD & 18 & 45,0 \\
SMP & 4 & 10,0 \\
SMA & 4 & 10,0 \\
\hline Lama Kerja & & \\
1- 10 tahun & 21 & 52,5 \\
11- 20 tahun & 15 & 37,5 \\
Lebih dari 20 tahun & 4 & 10,0 \\
\hline
\end{tabular}


Tabel 2. Pengaruh Promosi Kesehatan dan Keselamatan Kerja Terhadap Pengetahuan dan Sikap Pre-test dan Post-test Pemulung di TPA Terjun Medan Marelan.

\begin{tabular}{llll}
\hline Variabel & $\overline{\mathbf{X}}$ & SD & Nilai Z; Sig. \\
\hline Pengetahuan sebelum promosi K3 & 6,05 & 2,470 & \\
Pengetahuan sesudah promosi K3 & 10,40 & 2,023 & $-5,551 ; 0,000$ \\
Sikap sebelum promosi K3 & 55,48 & 7,232 & \\
Sikap sesudah promosi K3 & 55,75 & 6,315 & $-5,574 ; 0,000$ \\
\hline
\end{tabular}

Berdasarkan Tabel 1. menunjukan distribusi data responden berdasarkan umur 17-32 tahun sebanyak 6 orang (15,0\%), 33 - 48 tahun sebanyak 18 orang $(45,0 \%), 49-64$ tahun sebanyak 14 orang $(35,0 \%)$, dan $>64$ tahun sebanyak 2 orang $(5,0 \%)$. Distribusi data responden berdasarkan jenis kelamin jenis kelamin laki-laki sebanyak 24 orang $(60,0 \%)$, dan perempuan sebanyak 16 orang (40,0\%). Distribusi data responden berdasarkan pendidikan tidak tamat SD sebanyak 14 orang (35,0\%), tamat SD sebanyak 18 orang $(45,0 \%)$, tamat SMP sebanyak 4 orang $(10,0 \%)$, dan tamat SMA sebanyak 4 orang $(10,0 \%)$. Serta distribusi berdasarkan lama kerja 1-10 tahun sebanyak 21 orang (52,5\%), 11-20 tahun sebanyak 15 orang $(37,5 \%)$, lebih dari 20 tahun sebanyak 4 orang $(10,0 \%)$.

Analisis bivariat digunakan untuk melihat pengaruh peningkatan pengetahuan, dan sikap responden sebelum dan sesudah dilakukan perlakuan / intervensi. Data yang di kumpulkan dianalisis dengan uji Wilcoxon.

Tabel 3. Menunjukan bahwa rata-rata pengetahuan sebelum promosi kesehatan dan keselamatan kerja sebesar 6,05 dengan SD 2,470. Sedangkan rata-rata pengetahuan pemulung setelah dilakukan promosi kesehatan dan keselamatan kerja sebesar 10,40 dengan SD 2,023. Hasil uji statistik didapatkan nilai $\mathrm{p}=0,000$ maka dapat disimpulkan ada perbedaan yang signifikan antara rata-rata pengetahuan sebelum dan rata-rata sesudah dilakukan promosi kesehatan dan keselamatan kerja dan menunjukan rata-rata sikap sebelum promosi kesehatan dan keselamatan kerja sebesar 55,48 dengan SD 7,232. Sedangkan rata-rata sikap pemulung setelah dilakukan promosi kesehatan dan keselamatan kerja sebesar 58,75 dengan SD 6,315. Hasil uji statistik didapatkan nilai $\mathrm{p}=0,000$ maka dapat disimpulkan ada perbedaan yang signifikan antara rata-rata sikap sebelum dan rata-rata sikap sesudah dilakukan promosi kesehatan dan keselamatan kerja.

Pengaruh promosi kesehatan dan keselamatan kerja terhadap peningkatan pengetahuan pekerja informal di TPA Terjun Medan Marelan.

Berdasarkan hasil uji Wilcoxon pengetahuan pekerja mengenai kesehatan dan keselamatan kerja (K3) diperoleh $p$ sebesar 0,000 dan oleh karena itu nilai $p$ value $(0,000<0,05)$, sehingga ada pengaruh pengetahuan pada pekerja informal mengenai kesehatan dan keselamatan kerja (K3) di TPA Terjun Medan Marelan.

Pengetahuan adalah hasil penginderaan manusia, atau hasil tahu seseorang terhadap objek melalui indera yang dimilikinya (mata, hidung, telinga, dan sebagainya). Pengetahuan seseorang terhadap suatu objek mempunyai intensitas atau tingkat yang berbeda-beda (Wawan dan Dewi, 2012) Pengetahuan itu sangat erat hubungannya dengan pendidikan, dimana diharapkan bahwa dengan pendidikan yang tinggi maka orang tersebut akan semakin luas pula pengetahuannya. Akan tetapi perlu ditekankan, bukan berarti seseorang yang berpendidikan rendah mutlak berpengetahuan rendah pula.Hal ini mengingat bahwa peningkatan pengetahuan tidak mutlak diperoleh melalui pendidikan formal.Pengetahuan seseorang mengandung dua aspek yaitu aspek positif dan aspek negatif. Kedua aspek ini menentukan sikap seseoarng, semakin banyak aspek positif dan objek yang diketahui, maka akan menimbulkan sikap makin positif terhadap objek tertentu (Wawan dan Dewi, 2012) . 
Penelitian yang dilakukan oleh Firda Baihaq dengan judul Pengaruh Penyuluhan Terhadap Pengetahuan, Sikap dan Tindakan Mahasiswa Terkait Penggunaan Alat Pelindung Telinga Dari Bahaya Kebisingan Saat Mengerinda di Ruang Pengelasan Universitas Negeri Malang, hasil penelitian menunjukkan nilai Z -3,368 dan Asymp. Sig, (2-tailed) 0,000 pada variabel pengetahuan, nilai Z- 3973 dan Asymp. Sig, (2-tailed) 0,001 pada variabel Tindakan mahasiswa berarti lebih kecil dari pada 0,05. Kesimpulan dari pengujian hipotesis tersebut adalah terdapat pengaruh penyuluhuan terhadap pengetahuan, sikap, tindakan mahasiswa terkait penggunaan alat pelindung telingan dari bahaya kebisingan saat mengerinda di ruang pengelasan universitas negeri malang (Baihaq, 2017).

Penelitian yang dilakukan oleh Putri Kartika P dengan judul pengaruh penyuluhan $\mathrm{K} 3$ tentang $\mathrm{APD}$ terhadap pengetahuan dan sikap petani jeruk dalam penggunaan APD di desa suka sipilihen kabupaten karo tahun 2016. Hasil penelitian menunjukkan bahwa sebelum penyuluhan petani jeruk memiliki pengetahuan kurang pada kelompok perlakuan yaitu $(66,7 \%)$ dan kelompok kontrol $(60 \%)$ dan memiliki pengetahuan cukup pada kelompok perlakuan $(33,3 \%)$ dan kontrol (40\%). Setelah penyuluhan pengetahuan petani menjadi baik, pada kelompok perlakuan $(53,3 \%)$ pada kelompok kontrol menjadi $(6,7 \%)$ dan memiliki pengetahuan sedang pada kelompok perlakuan $(46,7 \%)$ dan kontrol $(33,3 \%)$. Sikap petani jeruh sebelum dilakukan penyuluhan memiliki sikap positif pada kelompok perlakuan $(13,3 \%)$ dan kelompok kontrol $(86,7 \%)$ dan memiliki sikap negative pada kelompok perlakuan $(86,7 \%)$ dan kontrol (13,3\%). Setelah mendapat penyuluhan sikap petani jeruk pada kelompok perlakuan kontrol menjadi positif masing-masing (86,7\%).Ini menunjukan bahwa penyuluhan K3 tentang APD berpengaruh terhadap pengetahuan dan sikap petani jeruk dalam penggunaan APD. Untuk itu diharapkan agar petani jeruk di Desa Suka Sipilihen dapat lebih disiplin dalam menggunakan APD untuk mengurangi penyakit akibat kerja (Panggabean, 2016).

Kemudian Penelitian yang dilakukan oleh Defri Afrianto dengan judul Pengaruh Penyuluhan Terhadap Pengetahuan,Sikap dan tindakan Petani
Paprika di Desa Kumbo Pasuruan Terkait Penggunaan Alat Pelindung Diri (APD) Dari Bahaya Pestisida Tahun 2014. Hasil penelitian menunjukkan sebelum penyuluhan, lebih dari 20 petani terdapat perbedaan yang signifikan pada skor median antara sebelum dan setelah penyuluhan. Sedangkan pada aspek tindakan, terjadi peningkatan jumlah penggunaan APD antara sebelum dan sesudah penyuluhan. Berdasarkan hasil penelitian, dapat diambil keputusan bahwa penyuluhan K3 yang dilakukan dapat memperbaiki pengetahuan, sikap dan tindakan petani paprika di desa kumbo terkait penggunaan APD dari bahaya pestisida (Afrianto, 2014).

Menurut peneliti pengetahuan pada pemulung di TPA Terjun Medan Marelan sangat kurang, ini sebelum dilakukannya promosi tentang kesehatan dan keselamatan kerja (K3). Karena, pemulung belum pernah sama sekali mendapatkan informasi tentang kesehatan dan keselamata kerja baik dari segi tentang penggunaan alat pelindung diri (APD) yang benar ataupun dapat mengenali potensi risiko bahaya yang terjadi dilingkungan kerja pemulung dengan hal ini maka peneliti melakukan promosi tentang kesehatan dan keselamatan kerja agar pemulung mendapatkan informasi/pendidikan tentang bagaimana mencegah atau mengenali bahaya risiko baik dari kecelakaan kerja maupun penyakit akibat kerja.Setelah dilakukannya promosi kesehatan dan keselamatan kerja (K3) maka ada peningkatan pengetahuan tentang kesehatan dan keselamatan kerja (K3) pada pemulung, pemulung mulai tahu untuk menggunakan alat pelindung diri (APD) serta fungsi dari alat pelindung diri seperti dengan menggunakan sarung tangan agar terhindar dari penyakit kulit yang diakibatkan dengan sampah yang mempunyai mikroorganisme yang beranekaragam serta menggunakan sepatu boots agar terhindar dari kecelakaan kerja dan lain sebagainya. Menurut peneliti Promosi kesehatan dan keselamatan kerja sangat berpengaruh dengan pengetahuan, agar pemulung sadar dengan lingkungan kerja yang tidak aman atau lingkungan kerja yang tidak sehat sehingga pemulung dapat menggunakan alat pelindung diri (APD) dengan baik sehingga ini dapat meminimalisir angka kecelakaan kerja serta penyakit akibat kerja pada pemulung di TPA Terjun Medan Marelan. 


\section{Pengaruh promosi kesehatan dan keselamatan kerja terhadap peningkatan sikap pekerja informal di TPA Terjun Medan Marelan.}

Berdasarkan hasil uji Wilxocon Sikap pekerja mengenai kesehatan dan keselamatan kerja diperoleh p 0,000 dan oleh karena itu nilai $p$ value $(0,000<0,05$ ), sehingga ada pengaruh sikap pekerja informal di TPA Terjun Medan Marelan.

Sikap adalah respon tertutup seseorang terhadapa stimulus atau objek tertentu yang sudah melibatkan faktor pendapat dan emosi yang bersangkutan.Sikap adalah perasaan, pikiran dan kecenderungan seseorang yang kurang lebih bersifat permanen mengenai aspek-aspek tertentu lingkungannya. Sikap merupakan reaksi atau respon yang masih tertutup dari seseorang terhadap stimulus atau objek. Sikap belum merupakan suatu tindakan atau aktivitas, akan tetapi merupakan predisposisi tindakan suatu perilaku. Sikap masih merupakan reaksi tertutup, bukan merupakan reaksi terbuka atau tingkah laku yang terbuka (Wawan dan Dewi, 2012).

Penelitian yang dilakukan oleh Firda Baihaq dengan judul Pengaruh Penyuluhan Terhadap Pengetahuan, Sikap dan Tindakan Mahasiswa Terkait Penggunaan Alat Pelindung Telinga Dari Bahaya Kebisingan Saat Mengerinda di Ruang Pengelasan Universitas Negeri Malang, hasil penelitian menunjukkan terdapat pengaruh penyuluhuan terhadap pengetahuan, sikap, tindakan mahasiswa terkait penggunaan alat pelindung telingan dari bahaya kebisingan saat mengerinda di ruang pengelasan universitas negeri malang (Baihaq, 2017).

Penelitian yang dilakukan oleh Putri Kartika P dengan judul pengaruh penyuluhan K3 tentang APD terhadap pengetahuan dan sikap petani jeruk dalam penggunaan APD di desa suka sipilihen kabupaten karo tahun 2016. Hasil penelitian menunjukkan bahwa setelah mendapat penyuluhan sikap petani jeruk pada kelompok perlakuan kontrol menjadi positif masing-masing (86,7\%). Ini menunjukan bahwa penyuluhan K3 tentang APD berpengaruh terhadap pengetahuan dan sikap petani jeruk dalam penggunaan APD. Untuk itu diharapkan agar petani jeruk di Desa Suka Sipilihen dapat lebih disiplin dalam menggunakan APD untuk mengurangi penyakit akibat kerja (Panggabean, 2016).

Hasil penelitian yang dilakukan oleh Ariyanto Tahun 2008 menyatakan ada pengaruh yang signifikan sosialisasi K3 terhadap pengetahuan K3 karyawan bagian produksi PT.MTG, ditujukkan dengan $p=0,000$, Ada pengaruh yang signifikan sosialisasi K3 terhadap sikap K3 karyawan bagian produksi PT.MTG, ditujukkan dengan $\mathrm{p}=0,000$, Ada pengaruh yang signifikan sosialisasi K3 terhadap motivasi K3 karyawan bagian produksi PT.MTG, ditujukkan dengan $p=0,000$ (Ariyanto, 2008).

Sikap pada pemulung di TPA Terjun Medan Marelan cukup, ini sebelum dilakukannya promosi tentang kesehatan dan keselamatan kerja (K3).Karena, pemulung sadar tentang potensi atau risiko penyakit akibat kerja yang sering dialami oleh pemulung seperti tidak memakai sarung tangan ketika sedang bekerja atau tidak cuci tangan jika hendak ingin memakan sesuatu hal-hal yang seperti ini sangat sering dilakukan oleh pemulung. Tetapi dengan adanya informasi yang diberikan peneliti tentang pentingnya menjaga kesehatan agar terhindar dari penyakit khusunya penyakit akibat kerja maka pemulung menjadi tahu, mau serta mampu untuk mengaplikasikannya dengan menggunakan sarung tangan agar terhindar dari penyakit kulit menggunakan masker serta mengkonsumsi obat obatan untuk meringankan batuk yang diderita oleh pemulung serta mencuci tangan sebelum hendak memakan agar terhindar dari penyakit diare.

\section{Kesimpulan dan Saran}

Berdasarkan hasil penelitian diperoleh bahwa promosi kesehatan dan keselamatan kerja berpengaruh terhadap pengetahuan dan sikap pada pemulung di TPA Terjun Medan Marelan Tahun 2018. Disarankan bagi pemerintah agar selalu mengadakan program promosi terkait Kesehatan dan Keselamatan Kerja (K3) pada pemulung di TPA Terjun Medan Marelan. Serta memperluas sasaran program Indonesia berbudaya K3 yaitu tidak hanya pada pekerja formal di industri besar atau berbadan hukum, namun juga pada setiap pekerja baik formal 
maupun informal yang berhadapan dengan bahaya dilingkungan kerja. Disarankan bagi pemulung untuk melakukan meningkatkan pengetahuan dan sikap yang baik untuk mencegah kemungkinan terjadinya gangguan kesehatan maupun kecelakaan kerja.Kemudian responden agar lebih disiplin dalam penggunaan alat pelindung diri (APD).

\section{DAFTAR PUSTAKA}

Afrianto D. 2014. Pengaruh Penyuluhan Terhadap Pengetahuan, Sikap Dan Tindakan Petani Paprika Di Desa Kumbo - Pasuruan Terkait Penggunaan Alat Pelindung Diri ( APD) Dari Bahaya Pestisida. J Kesehat dan Keselam Kerja [Internet]. 2014; Available from: http://repository.uinjkt.ac.id/dspace/bitstream /123456789/25507/1/defri afrianto - fkik.pdf

Ariyanto, N. 2008. Pengaruh Sosialisasi Keselamatan dan Kesehatan Kerja (K3) terhadap Pengetahuna, Sikap dan Motivasi Karyawan bagian Produksi PT Mataram Tunggal Garment Yogyakarta. Yogyakarta: Abstrak Ilmu Kesehatan Kerja UGM

Baihaq F.2017. Pengaruh Penyuluhan terhadap Pengetahuan, Sikap, dan Tindakan Mahasiswa terkait Penggunaan Alat Pelindung Telinga Dari Bahaya Kebisingan Saat Menggerinda di Ruang Pengelasan Universitas Negeri Malang. Malang: Skripsi Universitas Negeri Malang Fakultas Ilmu Keolahragaan.

Kemenkes RI. 2011. Promosi Kesehatan di Daerah Bermasalah Kesehatan. Jakarta: Kemenkes Ri

Kholid, Ahmad, 2012. Promosi Kesehatan dengan pendekatan teori prilaku, media, dan aplikasinya. Perpustakaan Nasional: Katalog Dalam Terbitan (KDT). Jakarata : Rajawali Pers.

Laili Nurjannah HFA. "Hubungan Promosi Keselamatan Dan Kesehatan Kerja (K3) Dengan Perilaku K3 Pada Karyawan Sub Departemen Produksi. 2017;12(1).
Nasution NH. 2017. Analisis Sistem Pengolahan Sampah di TPA Terjun Kecamatan Medan Marelan Kota Medan. Medan: Skripsi FKM USU

Notoatmodjo, Soekidjo. 2012. Promosi kesehatan dan Perilaku Kesehatan. Jakarta : Rineka cipta

Nurfajrianti, R. 2017. Upaya Pemberdayaan Pemulung Sampah di Tempat Pembuangan Akhir (TPA) Desa Pabbentengang Kecamtan BAjeng Kabupaten Goa. Makassar: Skripsi Fakultas Dakwah dan Komunikasi UIN Alauddin

Panggabean P. 2016. Pengaruh Penyuluhan K3 Tentang APD Terhadap Pengetahuan dan Sikap Petani Jeruk Dalam Penggunaan APD di Desa Suka Sipilihen Kabupaten Karo Tahun 2016. Medan: Skripsi FKM USU

Rafiah Maharani Pulungan, Triana B. Promosi keselamatan dan kesehatan kerja (K3) Terhadap Peningkatan Pengetahuan dan Sikap Tentang Penggunaan Alat Pelindung Diri (APD) Di Laboratorium Pada Siswa SMK Kimia Tunas Harapan Jakarta Timur. Jurnal Ilmu Kesehatan 1:99-104.

Siregar FS. 2017. Hubungan Perilaku Pemulung dengan Gangguan Kesehatan Kulit di Tempat Pembuangan Akhir Sampah di Kelurahan Terjun Kecamatan Medan Marelan. Medan: FKM USU

Yanti, K. 2011. Hubungan Perilaku dengan Kecelakaan Kerja Peternak Ayam Ras di Kecamatan Tilatang Kamang Kabupaten Agam Tahun 2011. Padang: Skripsi Ilmu Kesehatan Masyarakat Universitas Andalas

Wawan dan Dew. 2012. Teori dan Pengukuran Pengetahuan dan, Sikap dan Perilaku Manusia. Yogyakarta : Nuha Medika Oktober. PP. 6 